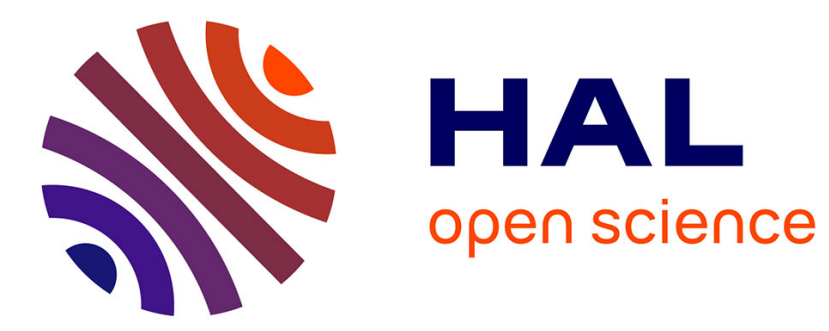

\title{
Atmosphere-soil carbon transfer as a function of soil depth
}

\author{
J. Balesdent, Isabelle Basile-Doelsch, Joel Chadoeuf, Sophie S. Cornu, \\ Delphine Derrien, Zuzana Fekiacova, Christine Hatté
}

\section{- To cite this version:}

J. Balesdent, Isabelle Basile-Doelsch, Joel Chadoeuf, Sophie S. Cornu, Delphine Derrien, et al.. Atmosphere-soil carbon transfer as a function of soil depth. Nature, 2018, 559 (7715), pp.599-602. 10.1038/s41586-018-0328-3 . hal-02073138

\section{HAL Id: hal-02073138 https://hal.science/hal-02073138}

Submitted on 21 Mar 2019

HAL is a multi-disciplinary open access archive for the deposit and dissemination of scientific research documents, whether they are published or not. The documents may come from teaching and research institutions in France or abroad, or from public or private research centers.
L'archive ouverte pluridisciplinaire HAL, est destinée au dépôt et à la diffusion de documents scientifiques de niveau recherche, publiés ou non, émanant des établissements d'enseignement et de recherche français ou étrangers, des laboratoires publics ou privés. 
1 Atmosphere-soil carbon transfer as a function of soil depth

Jérôme Balesdent ${ }^{1 *}$, Isabelle Basile-Doelsch ${ }^{1}$, Joël Chadoeuf ${ }^{2}$, Sophie Cornu ${ }^{1}$, Delphine Derrien ${ }^{3}$, Zuzana Fekiacova ${ }^{1} \&$ Christine Hatté $^{4}$

${ }^{1}$ Aix-Marseille Univ, CNRS, IRD, INRA, Coll France, CEREGE, Aix en Provence, France.

${ }^{2}$ INRA UR 1052, Avignon, France.

${ }^{3}$ INRA UR Biogéochimie des Ecosystèmes Forestiers, Nancy, France.

${ }^{4}$ Laboratoire des Sciences du Climat et de l'Environnement, UMR 8212 CEA-CNRS-UVSQ, Université ParisSaclay, Gif-sur-Yvette, France.

*e-mail: jerome.balesdent_a_inra.fr

The exchange of carbon between soil organic carbon (SOC) and the atmosphere affects the climate ${ }^{1,2}$ and-because of the importance of organic matter to soil fertilityagricultural productivity ${ }^{3}$. The dynamics of topsoil carbon has been relatively well quantified $^{4}$, but half of the soil carbon is located in deeper soil layers (below 30 centimetres) ${ }^{5-7}$, and many questions remain regarding the exchange of this deep carbon with the atmosphere ${ }^{8}$. This knowledge gap restricts soil carbon management policies and limits global carbon models ${ }^{1,9,10}$. Here we quantify the recent incorporation of atmosphere-derived carbon atoms into whole-soil profiles, through a meta-analysis of changes in stable carbon isotope signatures at 112 grassland, forest and cropland sites, across different climatic zones, from 1965 to 2015 . We find, in agreement with previous work $^{5,6}$, that the deeper 30-100 centimetres of soil (the subsoil) contains on average 47 per cent of the top metre's SOC stocks. However, this subsoil accounts for just $19 \%$ of the SOC that is newly incorporated (within the past 50 years) into the top metre. Globally, the median depth of recent carbon incorporation in mineral soil is 10 centimetres. Variations in the relative allocation of carbon to deep soil layers are better explained by the aridity index than by mean annual temperature. Land use for crops reduces the incorporation of carbon into the soil surface layer, but not into deeper layers. Our results suggest that SOC dynamics and its responses to climatic control or land use are strongly dependent on soil depth. We propose that using multilayer soil modules in global carbon models, tested with our data, could help to improve our understanding of soil-atmosphere carbon exchange. 
The size of the Earth SOC reservoir is estimated to be around 1,500 gigatonnes of carbon $(\mathrm{Gt} \mathrm{C})$ in the first metre, excluding permafrost $\operatorname{areas}^{6}$, making it a huge potential source or sink for atmospheric carbon (which increases by $+4.4 \mathrm{Gt} C$ per year) ${ }^{11}$. The future response of this soil compartment could substantially affect not only the climate but also global food production (through the role of organic matter in soil fertility), as well as the stability or resilience of ecosystems ${ }^{3}$. About half of this carbon is located at depths below $30 \mathrm{~cm}$ (refs. $\left.{ }^{5,6}\right)$. However, although the dynamics of topsoil carbon has been relatively well quantified, especially thanks to long-term experiments carried out over generations ${ }^{4}$, major questions remain about how to estimate changes in deep-soil carbon and the processes involved. Decision-makers and ecosystem managers are thus deprived of any references for the management of the deep carbon stock. Similarly, when modelling the Earth system and the global carbon cycle, the scientific community also constantly faces the problem of modelling the dynamics of deep carbon ${ }^{9,10,12}$.

Neither absolute changes in carbon stocks nor carbon fluxes in the deep soil horizons can be quantified by direct measurement. Owing to the very low carbon concentrations (on average less than $5 \mathrm{~g} \mathrm{~kg}^{-1}$ at depths of $80 \mathrm{~cm}$ ), spatial heterogeneity and slow changes, temporal variations in stocks are smaller than measurement accuracy. Evidence for deep carbon changes is therefore exceptional ${ }^{13,14}$. Information on incoming fluxes resulting from root mortality and exudation by living roots is not accessible without tracers. In addition, in situ quantification of the outflow from the organic reservoir - which occurs mainly through heterotrophic respiration of the organic matter decomposers, in the form of $\mathrm{CO}_{2}$ production-is very difficult, if not impossible, because the $\mathrm{CO}_{2}$ efflux mixes up heterotrophic respiration and root autotrophic respiration ${ }^{15}$. Isotopic methods are therefore appropriate for tracing deep carbon dynamics. The radiocarbon age of deep carbon is indicative of its slow turnover ${ }^{16-19}$, but ${ }^{14} \mathrm{C}$ dating, which provides mean ages, does not estimate the exact proportions of active and stable carbon ${ }^{17-20}$. Here we propose a stable-isotope-based observation of the actual depth distribution of soil carbon ages. It relies on sites that are marked by a natural change in the ${ }^{13} \mathrm{C} /{ }^{12} \mathrm{C}$ ratio of the vegetation at a known date. This is equivalent to the continuous in situ labelling of the atmospheric carbon atoms that have been incorporated into soil organic matter for a known duration, have eventually replaced pre-existing organic carbon, and have been retrieved at the date of sampling ${ }^{21}$.

We conducted a meta-analysis of 112 such sites (Extended Data Fig. 1), where the labelling ranged from 4 to 4,000 years. At each site, the technique provides an indication of 
carbon age - that is, the proportion of carbon that is younger than the labelling duration; metaanalysis of similar sites with varied durations provides an age probability distribution ${ }^{17}$. Our study includes most of the world's biomes except boreal zones, and is evenly distributed among forests, grasslands and croplands.

We quantified carbon distribution in the two-dimensional age-depth continuum ${ }^{22}$, the depth distribution of carbon incorporation in soil over the past 50 years, and the dependence of these factors on climate and land use. We also summarized depth distributions in terms of two layers, $0-30 \mathrm{~cm}$ (topsoil) and 30-100 cm (subsoil) — an arbitrary cut-off, but one that is often used in carbon inventories ${ }^{6}$. Our results, which are based on original observations, are independent of any data sets or modelling results from other studies.

Figure 1 depicts individual data showing the proportion of new carbon - that is, the proportion of SOC that derives from new vegetation - as a function of time. At all depths, a minor proportion of soil carbon is renewed rapidly (within ten years). Nine sites at which a vegetation signature change occurred more than 1,000 years ago reveal the incomplete replacement of carbon, that is, the presence of millennia-old soil carbon, at depth but not in the topsoil.

The rate of carbon incorporation in the topsoil was, as expected, strongly dependent on environmental variables, in particular land use $(P<0.001)$ and mean annual temperature (MAT; $P<0.05$ ) (Extended Data Table 1). For the subsoil, by contrast, we found no relationship between carbon age and land use, and only a weak relationship with temperature $(P=0.1)$; instead, carbon age was more affected by the ratio of precipitation to potential evapotranspiration ${ }^{23}(P<0.01$; Extended Data Table 2$)$. This observation reinforces the results of ref. ${ }^{9}$, which showed that the relationship between ecosystem carbon turnover time and precipitation is pervasive and underestimated by models.

To analyse the age distribution with depth under comparable environmental conditions, we selected a homogeneous subset of sites, namely a group of forests and grasslands under warm and moist climates (with MATs higher than $17^{\circ} \mathrm{C}$, annual precipitation of more than $1,000 \mathrm{~mm}$, and precipitation/evapotranspiration ratios greater than 0.8). Figure 2 and Extended Data Table 3 depict the detailed depth distribution of carbon ages throughout this panel of soils. This description of carbon dynamics in time-depth space highlights its strong dependence on both variables. The dynamics of subsoil carbon is around seven times slower than that of topsoil carbon (that is, it takes seven times longer to reach the same proportion of renewed carbon; Extended Data Fig. 2). In deep layers, the age distribution reveals the small but non-negligible 
direct incorporation of photosynthetically fixed carbon through deep roots or soluble carbon (for the youngest carbon), and the predominance of carbon that is older than 1,000 years. Midprofile horizons (20-70 cm) are dominated by carbon of intermediate ages (100 to 1,000 years), which can be considered to result from the slow downward movement of carbon ${ }^{16,24}$. Carbon incorporation in the 100-200-cm layer has been quantified in only a few studies and averaged $5 \pm 3 \%$ ( 1 standard deviation) of soil carbon after 50 years.

We calculated the amount of carbon incorporated into each layer $\left(C_{\text {new }}\right.$, in units of $\mathrm{kg} \mathrm{C} \mathrm{m}{ }^{-2}$ ) for each site. In our database, the SOC found in the subsoil layer represents $47 \%$ of the total stock found in the entire top metre of soil, in agreement with the percentage of $47 \%$ to $52 \%$ reported globally ${ }^{5,6}$. To express the incorporation of new carbon in depth on the basis of a

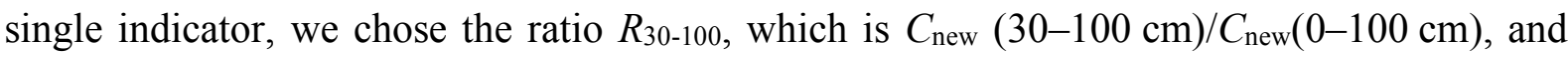
analysed its dependence on land use, climate and time in the 0- to 200-year-old sites (Extended Data Table 4). We found that $R_{30-100}$ is strongly dependent on land use $(P<0.001)$. The mean values of $R_{30-100}$ (50 years) are 19\%, 21\% and 29\% for forests, grasslands and croplands, respectively. The relatively deeper carbon incorporation in croplands concerns all layers below a depth of $10 \mathrm{~cm}$ and cannot be explained only by soil mixing due to ploughing, as the depth of this mixing does not exceed $30 \mathrm{~cm}$ (Fig. 3). Croplands incorporate less new carbon in their topsoils than do forests and grasslands, whereas in subsoil the amount of incorporated carbon is similar (Extended Data Tables 1 and 2). This is consistent with the general reduction in carbon input at the soil surface ${ }^{25}$ that results from the removal of above-ground biomass during harvesting. $R_{30-100}$ also depends on the precipitation/evapotranspiration index $(P<0.005)$, and is weakly dependent on MAT ( $P<0.1$; Extended Data Table 4), in accordance with the deeper rooting that takes place under dry climates, and possibly the more frequent occurrence of deep soils at low latitudes. The world average value of $\mathrm{R}_{30-100}$ (50 years) is $19 \%$ ( $\pm 4 \%$; $95 \%$ confidence interval) (Fig. 3). The overall shallow incorporation of carbon can be expressed by the median depth of carbon incorporated in the last 50 years: $9 \pm 1 \mathrm{~cm}( \pm 95 \%$ confidence interval) in forests, $10 \pm 2 \mathrm{~cm}$ in grasslands and $17.5 \pm 1.5 \mathrm{~cm}$ in croplands in our panel $(9.7 \pm$ $1.2 \mathrm{~cm}$ on average globally; Extended Data Table 5). Taking into account the 100-200-cm layer (when observed) would lower this median depth by $0.5 \mathrm{~cm}$.

This study provides an unprecedented estimate of, first, the SOC age distribution over the soil profile (Fig. 2), and, second the depth distribution of the carbon transferred from the atmosphere to soils (Fig. 3). The carbon-incorporation profiles can be compared with existing profiles of root biomass and above-ground inputs. The proportion of carbon that we found to 
be allocated to the subsoil is higher than the corresponding proportion of root biomass compiled in meta-analyses ${ }^{5,26}$. This can be explained on the one hand by the contribution of root exudates in addition to root mortality ${ }^{27}$, and on the other hand by reduced decay rates at depth ${ }^{24}$. The reduced decay rates could be related to several interacting processes, for example, reduced and scattered microbial biomass $^{8}$, stabilization by minerals ${ }^{8,18}$, and reduced priming effect (the latter being the stimulation of SOC decomposition by the supply of fresh carbon) ${ }^{28}$.

We measured the depth distribution of atmosphere-derived carbon incorporation over the past 50 years (50-year input). The depth distribution of the net change in soil carbon in the same time interval also depends on the loss of carbon older than 50 years during the period (50year output). In steady-state systems, the depth distribution of outputs would perfectly equal the depth distribution of inputs. But real systems are transient as a result of global changes in either carbon inputs (for example, increased net primary production, reduced carbon returns because of land-use change) or decay rates (for example, because of warming). On the basis of our meta-analysis, we argue that the depth distributions of carbon output and of carbon incorporation are very similar even in transient systems, for the following reason. In nonsteady-state systems, the delay associated with the downward movement of carbon may be suspected to result in 50-year outputs that are deeper than 50-year inputs, in a 'conveyor-like' dynamic system. But the $R_{30-100}$ ratio increases very slowly with time (by less than 0.001 per year; Extended Data Table 4). This means that the movement of carbon is slow and affects only long-term carbon dynamics, far later than the change expected in future decades. The depth distribution of net changes could differ from our distribution of new carbon only under the pressure of a driving force that affects old carbon in a very different way to the new carbon, such as de-freezing ${ }^{29}$ or major changes in deep carbon inputs leading to additional priming effects $^{28}$.

Our study also reveals that the steep age gradient with depth (Fig. 2) could be a source of bias in the representation of carbon dynamics if depth is not handled properly. For instance, if we consider three commonly used reference layers $-0-10 \mathrm{~cm}, 0-20 \mathrm{~cm}$ and $0-30 \mathrm{~cm}-$ we find that their median ages differ considerably, being 23, 50 and 92 years, respectively. Projecting the decay-rate parameters observed in the topmost part of soils onto thicker layers would bias future projections of changes in carbon. The kinetics of carbon incorporation further reveals a substantial turnover over the time range of centuries (Figs. 1, 2 and Extended Data Fig. 2) - that is, between the 'decadal' and 'millennial' compartments of present carbon 
models ${ }^{1,7,30}$ — arguing for a more realistic description of carbon storage in terms of continuous time ranges ${ }^{30}$.

Our results show that SOC dynamics and their responses to climatic control or land use are strongly depth dependent. A better representation of deep carbon dynamics has been called for, together with other processes, to improve ecosystem carbon models ${ }^{7,12,19}$. Our observations support the use of multilayer SOC modules in Earth system models, which our data could help to test.

Online content Any Methods, including any statements of data availability and Nature Research reporting summaries, along with any additional references and Source Data files, are available in the online version of the paper

Received 12 September 2017; accepted 4 May 2018.

1. Ahlström, A., Schurgers, G., Arneth, A. \& Smith, B. Robustness and uncertainty in terrestrial ecosystem carbon response to CMIP5 climate change projections. Environ. Res. Lett. 7, 044008 (2012).

2. Heimann, M. \& Reichstein, M. Terrestrial ecosystem carbon dynamics and climate feedbacks. Nature 451, 289-292 (2008).

3. Tiessen, H., Cuevas, E. \& Chacon, P. The role of soil organic matter in sustaining soil fertility. Nature 371, 783-785 (1994).

4. Rasmussen, P. E. et al. Long-term agroecosystem experiments: assessing agricultural sustainability and global change. Science 282, 893-896 (1998).

5. Jobbágy, E. G. \& Jackson, R. B. The vertical distribution of soil organic carbon and its relation to climate and vegetation. Ecol. Appl. 10, 423-436 (2000).

6. Hiederer, R. \& Köchy, M. Global Soil Organic Carbon Estimates and the Harmonized World Soil Database (Public. Office EU, 2011).

7. Todd-Brown, K. E. O. et al. Causes of variation in soil carbon simulations from CMIP5 Earth system models and comparison with observations. Biogeosciences 10, 1717-1736 (2013).

8. Rumpel, C. \& Kögel-Knabner, I. Deep soil organic matter-a key but poorly understood component of terrestrial C cycle. Plant Soil 338, 143-158 (2011).

9. Carvalhais, N. et al. Global covariation of carbon turnover times with climate in terrestrial ecosystems. Nature 514, 213-217 (2014).

10. Tian, H. Q. et al. Global patterns and controls of soil organic carbon dynamics as simulated by multiple terrestrial biosphere models: current status and future directions. Glob. Biogeochem. Cycles 29, 775-792 (2015).

11. Le Quéré, C. et al. Global carbon budget 2016. Earth Syst. Sci. Data 8, 605-649 (2016). 
12. Luo, Y. et al. Toward more realistic projections of soil carbon dynamics by Earth system models. Glob. Biogeochem. Cycles 30, 40-56 (2016).

13. Guan, X. K. et al. Soil carbon sequestration by three perennial legume pastures is greater in deeper soil layers than in the surface soil. Biogeosciences 13, 527-534 (2016).

14. Hobley, E., Baldock, J., Hua, Q. \& Wilson, B. Land-use contrasts reveal instability of subsoil organic carbon. Glob. Change Biol. 23, 955-965 (2017).

15. Chen, G., Yang, Y. \& Robinson, D. Allometric constraints on, and trade-offs in, belowground carbon allocation and their control of soil respiration across global forest ecosystems. Glob. Change Biol. 20, 16741684 (2014).

16. Elzein, A. \& Balesdent, J. Mechanistic simulation of vertical distribution of carbon concentrations and residence times in soils. Soil Sci. Soc. Am. J. 59, 1328-1335 (1995).

17. Sierra, C. A., Müller, M., Metzler, H., Manzoni, S. \& Trumbore, S. E. The muddle of ages, turnover, transit, and residence times in the carbon cycle. Glob. Change Biol. 23, 1763-1773 (2017).

18. Mathieu, J., Hatté, C., Balesdent, J. \& Parent, E. Deep soil carbon dynamics are driven more by soil type than by climate: a worldwide meta-analysis of radiocarbon profiles. Glob. Change Biol. 21, 4278-4292 (2015).

19. He, Y. et al. Radiocarbon constraints imply reduced carbon uptake by soils during the 21 st century. Science 353, 1419-1424 (2016).

20. Ahrens, B. et al. Bayesian calibration of a soil organic carbon model using $\triangle 14 \mathrm{C}$ measurements of soil organic carbon and heterotrophic respiration as joint constraints. Biogeosciences 11, 2147-2168 (2014).

21. Balesdent, J. \& Mariotti, A. in Mass Spectrometry of Soils (eds Boutton, T. W. \& Yamasaki, S. I.) 83-111 (Marcel Dekker, New York, 1996)

22. Lehmann, J. \& Kleber, M. The contentious nature of soil organic matter. Nature 528, 60-68 (2015).

23. Trabucco, A. \& Zomer, R. Global Aridity Index (Global-Aridity) and Global Potential Evapo-Transpiration (Global-PET) Geospatial Database (CGIAR, Consortium for Spatial Information, 2009).

24. Guenet, B. et al. The relative importance of decomposition and transport mechanisms in accounting for soil organic carbon profiles. Biogeosciences 10, 2379-2392 (2013).

25. Guo, L. \& Gifford, R. Soil carbon stocks and land use change: a meta-analysis. Glob. Change Biol. 8, 345360 (2002).

26. Schenk, H. J. \& Jackson, R. B. The global biogeography of roots. Ecol. Monogr. 72, 311-328 (2002).

27. Strand, A. E., Pritchard, S. G., McCormack, M. L., Davis, M. A. \& Oren, R. Irreconcilable differences: fineroot life spans and soil carbon persistence. Science 319, 456-458 (2008).

28. Fontaine, S. et al. Stability of organic carbon in deep soil layers controlled by fresh carbon supply. Nature 450, 277-280 (2007). 
29. Koven, C. D. et al. Permafrost carbon-climate feedbacks accelerate global warming. Proc. Natl Acad. Sci. USA 108, 14769-14774 (2011).

30. Manzoni, S., Katul, G. G. \& Porporato, A. Analysis of soil carbon transit times and age distributions using network theories. J. Geophys. Res. 114, G04025 (2009).

Acknowledgements We thank C. Marol, S. Milin and P. Signoret for contributing to additional isotopic analyses, as well as the scientists who provided numerical data from their published studies. We thank the French Agence Nationale de la Recherche for funding through the projects Dedycas (14-CE01-0004) and Equipex Aster-CEREGE (ANR-10-EQPX-24) and for supporting the Institute National de la Recherche Agronomique (INRA) Laboratory UR-1138 through the Laboratory of Excellence ARBRE (ANR-11-LABX-0002-01). This is a LSCE contribution \# 6464 .

Author contributions J.B. led the study and drafted the manuscript. All authors contributed equally to data provision and processing, and commented on and provided edits to the original manuscript. J.C. supervised the statistical analysis.

Competing interests The authors declare no financial competing interests.

Extended data is available for this paper

Supplementary information is available for this paper

Correspondence and requests for materials should be addressed to J.B. 


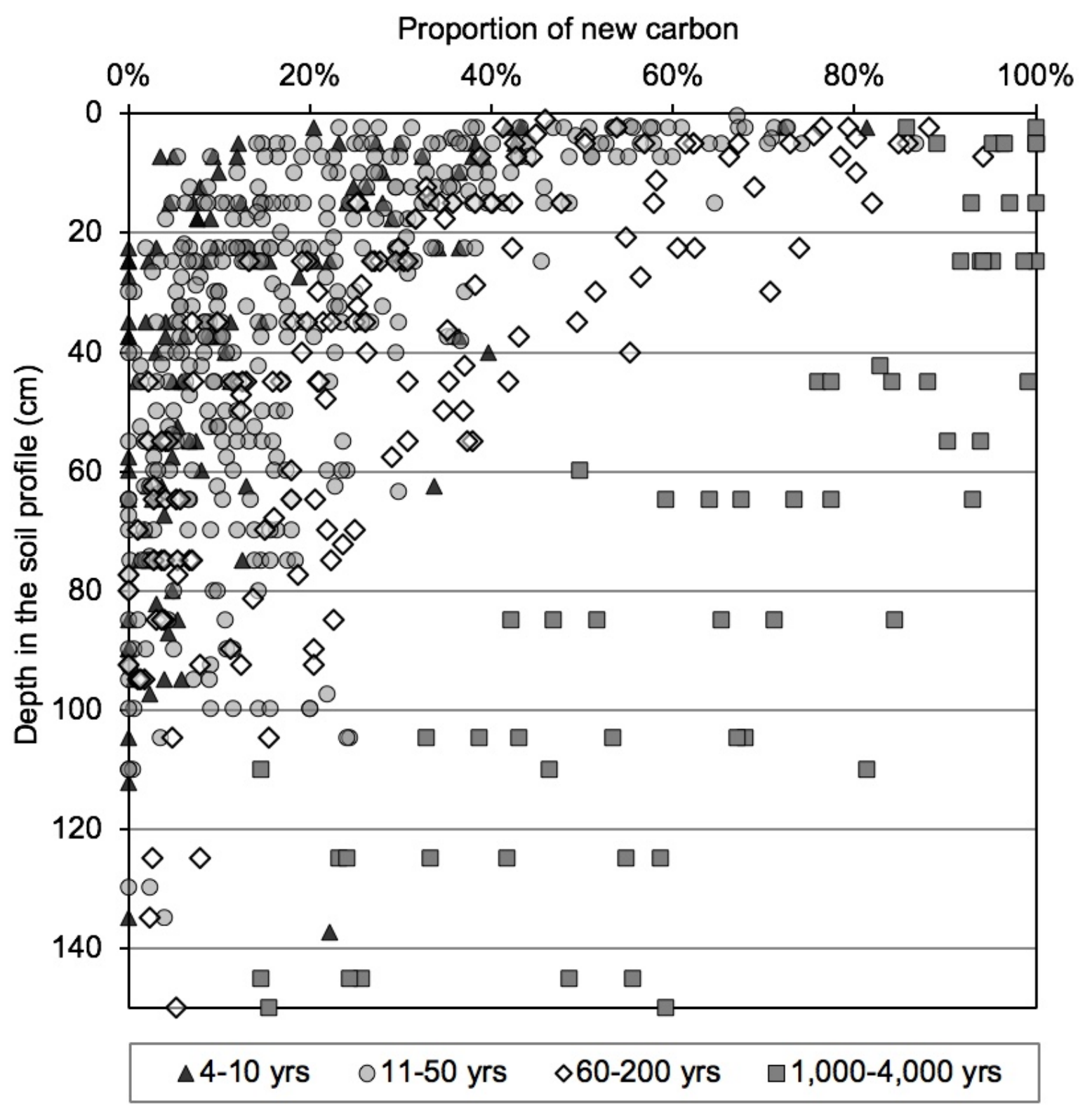

249 Fig. 1 | Observed proportions of new carbon in 112 soil profiles. In each soil sample, the

250 proportion $p$ of new carbon atoms was determined by the change in the soil carbon ${ }^{13} \mathrm{C}$ signature

251 following a change in the ${ }^{13} \mathrm{C}$ signature of the vegetation for a given duration $t ; p$ is the

252 proportion of carbon younger than $t^{21}$. Data are presented in four classes of duration $t$. 


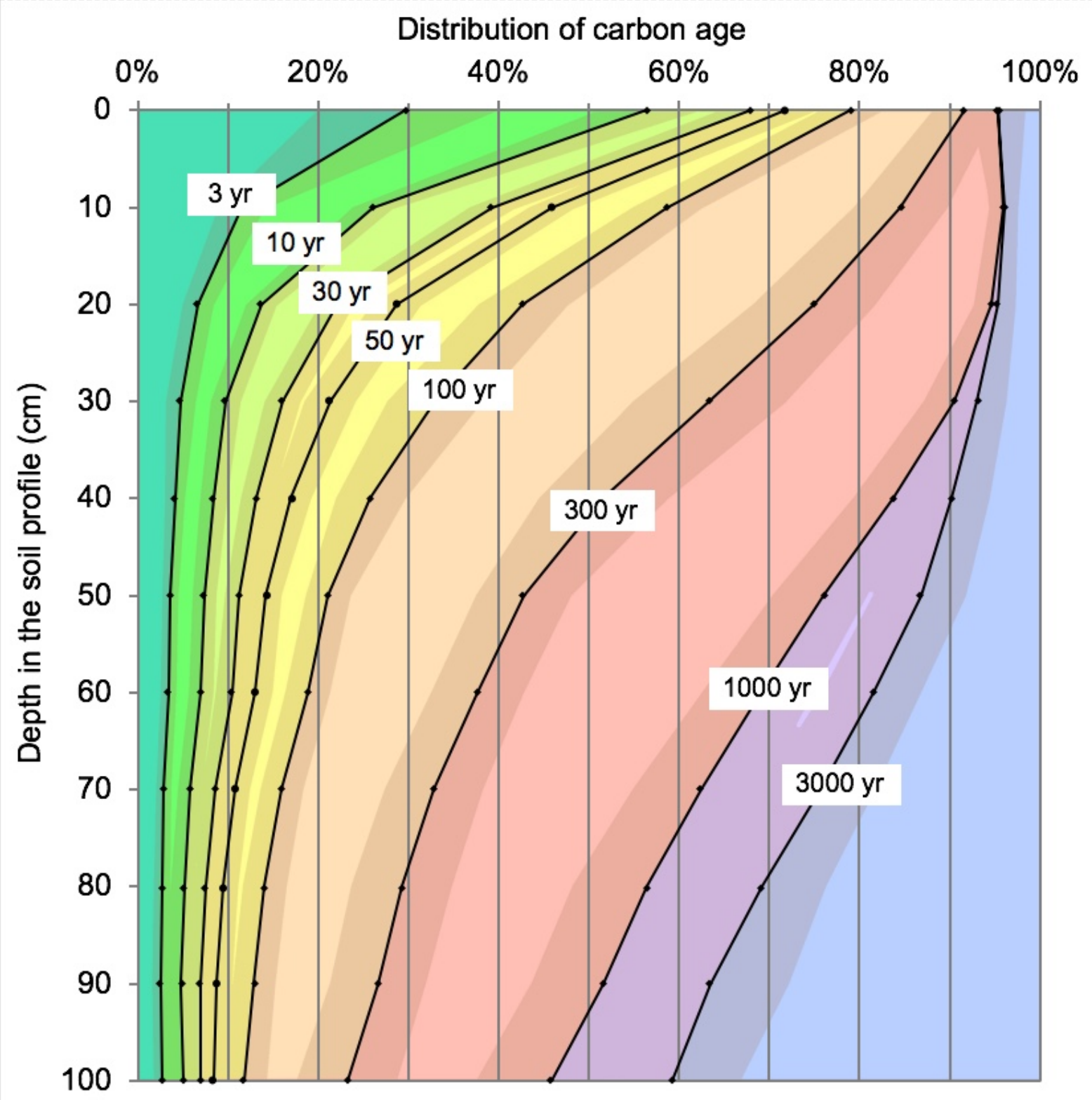

Fig. 2 | Meta-analysis of carbon age distribution over 55 tropical grassland and forest soil profiles. At each depth, the proportion of carbon aged less than time $t$ ( 3 years, 10 years and so on) was fitted by a bi-exponential regression of $t$ (Extended Data Table 3). Grey bands represent \pm 1 standard error of the estimated mean. The median age of soil carbon increases from seven years at depth $0 \mathrm{~cm}$ to 1,250 years at $100 \mathrm{~cm}$. Integration of the carbon content in each layer demonstrates that the carbon of age less than 50 years represents $45 \%$ of topsoil carbon ( 0 $30 \mathrm{~cm})$ and $13 \%$ of deep carbon $(30-100 \mathrm{~cm})$. 


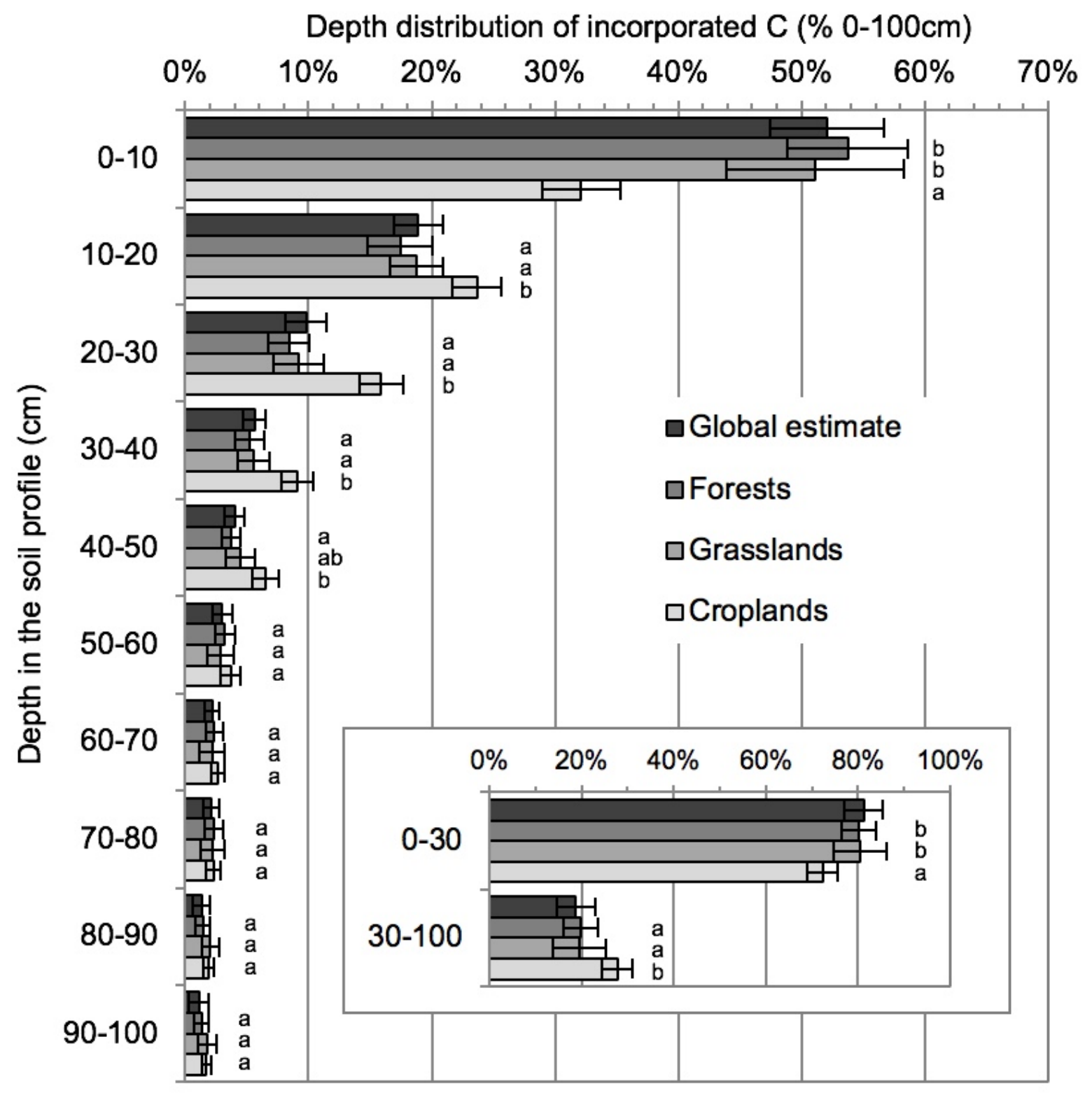

Fig. 3 | Depth distribution of the carbon that has been transferred from the atmosphere to soil organic matter between 1965 and 2015. The amount of carbon per 10-cm increment is expressed as a proportion of the total carbon incorporated in the top metre. The value for each land use is the mean of the observed profiles, and the value for the whole Earth was estimated by multivariate linear model extrapolation to the world's biomes. Error bars represent the 95\% confidence interval of the mean or estimate; within each increment, land uses followed by the same letter ( $a$ or $b$ ) do not differ significantly. The small shift between the global estimate and the observed values reflects the differences in soil-climate conditions between the global average and the observation panel. 
Study sites

We compiled published data sets from 47 peer-reviewed articles, together with original data, on mineral soil ${ }^{13} \mathrm{C} /{ }^{12} \mathrm{C}$ changes in places where the ${ }^{13} \mathrm{C} /{ }^{12} \mathrm{C}$ ratio of the vegetation has been shifted for known durations (see Supplementary Information). We analysed a total of 112 pairs of mineral soil profiles: 108 pairs in which the predominant vegetation has changed from the C3 photosynthetic type to the C4 type, or vice versa, and four pairs from free-air carbonenrichment (FACE) experiments, where the ${ }^{13} \mathrm{C}$ signature of added carbon dioxide has labelled plant-derived material (Extended Data Fig. 1; see references in Supplementary Information. At each site, two plots with a common history (one with changed and one with unchanged vegetation) were analysed. The isotopic difference between the two profiles was used to calculate the proportion of new carbon through an isotope-mixing equation, which is not biased by additional isotopic effects in soils ${ }^{21}$.

Most of the world's biomes are represented; the land uses include grasslands and savannas (34\%), forests and woodlands (30\%), and annual and perennial crops (36\%), from 24 countries between latitudes $29^{\circ} \mathrm{S}$ and $57^{\circ} \mathrm{N}$ (Extended Data Fig. 1). We selected studies that fulfil the following criteria: the age of change should be known or estimated; the observed depth should be more than $60 \mathrm{~cm}$ or reach bedrock; and the difference in the $\delta^{13} \mathrm{C}$ of the vegetation between the reference and the study site should be $5 \%$ or more in the case of mixed vegetation that include both photosynthetic types. The duration of vegetation change ranged from 4 years to 4,000 years. Authors estimated the dates of change through controlled experiments, enquiries, historical records, or airborne surveys. Changes in isotope signature that occurred more than 1,000 years ago (nine sites) were associated with interacting climate- and maninduced changes in vegetation. In those cases, dates were estimated by the authors from local or regional proxies of palaeovegetation change (for example, pollen/charcoal combined with radiocarbon dating). When the period after vegetation change was expressed by the authors as a range (for changes older than 200 years), we used the mid-value of the range.

Mean climatic data were obtained either from data reported in the article $(n=103)$ or, if missing $(n=9)$, from the CRU Group/Oxford/International Water Management Institute (IWMI) 10-minute mean climate grids for global land areas for the period 1961 to 1990 (ref. $^{31}$ ). We compared grid versus declared climatic data in the database: for annual precipitation, the mean CRU grid/declared ratio is $0.98 \pm 0.15$ (standard deviation); for MAT, the mean difference between CRU grid and declaration is $-0.15 \pm 1.1^{\circ} \mathrm{C}$. Topsoil clay content was either 
obtained from authors' statements or assumed to be the median value of the texture class mentioned. Mean annual aridity indexes, P/PET (annual precipitation/potential evapotranspiration $)^{23}$ - a better indicator of hydric impact on both net primary production and microbial activity than precipitation alone - were obtained from the Food and Agriculture Organization 10-minute mean climate grids for global land areas for the period 1950 to 2000 $\left(\right.$ ref. $\left.^{23}\right)$.

\section{Proportion of new carbon and data pre-processing}

For each site, the natural ${ }^{13} \mathrm{C}$-labelling technique uses two plots, which were initially identical, and have been differentiated during the last $t$ years by two types of vegetation that differ in their $\delta^{13} \mathrm{C}$. We use the terms 'reference' ('ref') for the plot at which the vegetation type at the date of sampling is the closest to that of the initial vegetation, and 'studied plot' ('s') for the plot with the new type of vegetation. Most authors described carbon content and isotopic data profiles as successive layers, each one sampled between two depths $\left(z_{1}, z_{2}\right)$. For each layer $\left(z_{1}\right.$, $z_{2}$ ), we define $C$ as the carbon stock in the horizon (in $\mathrm{kg} \mathrm{m}^{-2}$ ); $f_{\text {new }}$ as the proportion of new carbon (that is, derived from the new vegetation) (Fig. 1); and $C_{\text {new }}$ as the stock of new carbon in the horizon (in $\mathrm{kg} \mathrm{m}^{-2}$ ). $C, f_{\text {new }}$ and $C_{\text {new }}$ were either obtained from the authors' papers $(n=30)$, or calculated from observed variables as follows. $C$ was calculated from carbon concentration, $[\mathrm{C}]$ (in $\mathrm{mg} \mathrm{g}^{-1}$ ), and bulk density, $\rho$, according to $C=[\mathrm{C}] \times \rho \times\left(z_{2}-z_{1}\right)$, where $\rho$ was either from the authors' data or (in 41 cases) estimated from [C] according to Alexander's ${ }^{32}$ equation. $f$ and $C_{\text {new }}$ were calculated according to the equations ${ }^{21}$ :

$f_{\text {new }}=\left(\delta\right.$ soil $_{\mathrm{s}}-\delta$ soil $\left.1_{\text {ref }}\right) / \Delta \delta$ veg

$C_{\text {new }}=f_{\text {new }} \times C$

where $\delta$ soil $_{\mathrm{s}}$ and $\delta$ soil $\mathrm{ref}_{\text {ref }}$ are the $\delta^{13} \mathrm{C}$ values of SOC from the study and reference plots; and $\Delta \delta$ veg is the difference in vegetation $\delta^{13} \mathrm{C}$ between the study and reference plots and was determined from plant or litter samples. The $\delta$ soil $1_{\text {ref }}$ in each horizon was obtained from the reference soil collected at the same depth as the soil of the study plot. In accordance with the limit of resolution of the method, 27 horizons in deep layers had negative $f_{\text {new }}$ values; in this case, we considered $C_{\text {new }}$ to be 0 . The resulting overestimation of average new carbon was negligible. In cases in which the sampling depth differed at the reference and studied plots, we calculated $\delta$ soil $l_{\mathrm{s}}$ by linear interpolation of the two nearest observed depths. Equation (1) typically accounts for the various ${ }^{13} \mathrm{C}$ enrichments that occur during organic carbon decay or historical changes ${ }^{21}$, with the sole criterion that these enrichments are similar in the study and 
reference soils. Equation (1) neglects the dark fixation of carbon atoms ${ }^{33}$ that would have the isotopic composition of atmospheric $\mathrm{CO}_{2}$.

\section{Depth distribution of new carbon}

We calculated depth distributions for the subset of sites whose labelling duration was 200 years or less $(n=99$; Fig. 3$)$. The mean duration was 35 years. In order to compare similar depth intervals, we calculated the three variables $f_{\text {new }}$, cumulative carbon stock with depth $C(0, z)$ and $C_{\text {new }}(0, z) 10-\mathrm{cm}$ increments by linear interpolation of the observed horizons. For each $10-\mathrm{cm}$ depth interval $(z, z+0.1 \mathrm{~m})$, we computed the ratio $R=C_{\text {new }}(z,+10 \mathrm{~cm}) / C_{\text {new }}(0,100 \mathrm{~cm})$. When bedrock or the R horizon was described, a nil carbon content was attributed to these horizons. When profiles were not described down to a depth of one metre $(n=31$; most often $80 \mathrm{~cm}), C(0,100 \mathrm{~cm})$ was extrapolated from the maximum depth $z_{\max }$ using the linear regression $C(0,100 \mathrm{~cm})=a \times C\left(0, z_{\max }\right)+b$ over the entire data set and similarly for $C_{\text {new }}(0$, $100 \mathrm{~cm})$.

The median depth $z_{\text {median }}$ of new carbon was calculated for individual profiles as $C_{\text {new }}(0$, $\left.z_{\text {median }}\right)=C_{\text {new }}(0,100 \mathrm{~cm}) / 2$, by linear interpolation in the observed $C_{\text {new }}(0, z)$ function.

The variance of the ten ratios $R=C_{\text {new }}(z, z+10 \mathrm{~cm}) / C_{\text {new }}(0,10 \mathrm{~cm})$ at the ten depths $z=0,10, \ldots, 90 \mathrm{~cm}$, the ratio for the whole subsoil $C_{\text {new }}(30,100 \mathrm{~cm}) / C_{\text {new }}(0,100 \mathrm{~cm})$ and the median depth of new carbon were analysed by multivariate linear regression of time, land use and climatic variables (Extended Data Tables 3-5). Given that the average start date of labelling was 1965 , we consider that the regression value of $R$ for time $=50$ years stands for carbon incorporated in the time interval 1965-2015. World average values of carbon incorporation in deep soil layers, excluding permafrost areas, were obtained by weighting multivariate linear regression estimates of new carbon (Extended Data Tables 1, 2, 4 and 5) by the biome soil carbon inventories in ref. ${ }^{5}$. Multivariate linear regression used the mean value of each of the 112 observed profiles, with no weighting for the number of replicates or horizons, leading to less precise but unbiased estimation. When replicated, profile variability is provided in the database in the Supplementary Information. We used bootstrap procedures ${ }^{34}$ to express confidence on the estimated depth distribution or median age for the globe (Fig. 3 and Extended Data Table 6), or on the depth distribution of ages in tropical grasslands and forests (Fig. 2 and Extended Data Table 3). For that purpose, we drew $N=100,000$ independent profile bootstrap samples from the observed profiles. For each bootstrap sample, relationships with P/PET, MAT, land use and time were recomputed and used to calculate the values of the variables of 
interest. Standard deviations were then estimated as the standard deviation of these 100,000 values.

Statistical analyses were performed using the R packages Boot and Stats version 3.4.3.

\section{Analysis of the inference of vegetation change on the results}

The naturally labelled sites experienced varying degrees of perturbation compared with pristine ecosystems. Vegetation change may modify input or decay rates, leading to transient carbon dynamics. To investigate whether these changes themselves affect the depth distribution of new carbon, we tested the dependence on two additional variables that characterize the observed sites: the previous type of vegetation - either crops, grassland or forest, known for 109 sitesand the relative difference in carbon stock between study and reference plots, when known and when the reference resembled the previous vegetation type ( $n=88$ sites). The relative change $\Delta C_{\text {rel }}$ is calculated as:

$\Delta C_{r e l}=\left[C(0,100 \mathrm{~cm})_{\text {studied site }}-C(0,100 \mathrm{~cm})_{\text {reference site }}\right] / C(0,100 \mathrm{~cm})_{\text {reference site }}$

$\Delta C_{\text {rel }}$ is nil on average in the database, that is, it corresponds to the steady state $\left(\Delta C_{\text {rel }}=0.004 \pm 0.026, \pm\right.$ s.e.m. $)$; however, it does vary as a result of changes in inputs or dynamics in different directions. Mean durations of change are independent of previous vegetation in the statistical analysis: 31 years for previous grassland, 37 years for previous crops and 40 years for previous forests (excluding durations of more than 1,000 years, which involve no crop). $\Delta C_{\text {rel }}$ is not correlated with the duration of the change either.

Concerning the depth distribution of new carbon, that is, $R_{30-100}=C_{\text {new }}(30$ to $100 \mathrm{~cm}) / C_{\text {new }}(0$ to $100 \mathrm{~cm}), R_{30-100}$ is not correlated with $\Delta C_{\text {rel }}$ either in the whole data set $\left(r^{2}=0.002 ; n=88\right)$, or within the subsets of crops $\left(r^{2}=0.01 ; n=31\right)$, grasslands $\left(r^{2}=0.02\right.$; $n=24)$ or forests $\left(r^{2}=0.13 ; n=33\right)$. We also tested the previous vegetation type as an explanatory variable of $R_{30-100}$ in addition to the other variables of climate, present land use and time (that is, the variables in Extended Data Table 4). The additional variable was not a significant factor (previous forest versus previous crop: $P=0.88$; previous grassland versus previous crop: $P=0.52$; previous grass versus previous forest: $P=0.47$ ) and did not improve the model.

Concerning the proportion of new carbon in either topsoil or subsoil (that is, $f_{\text {new }}$ ), the previous vegetation type added as an explanatory variable in the statistical models of Extended Data Tables 1 and $2 \mathrm{w}$ as not a significant factors either $(P=0.49$ to 0.99$)$. By contrast, as an additional variable, $\Delta C_{\text {rel }}$ was highly significant for topsoil $(P<0.01)$ but was not for subsoil 
$(P=0.12)$. The effect is obvious given that both carbon change and new carbon are first driven by the relative change in inputs. This effect typically explains one of the results, namely the lower proportion of new carbon in cropland topsoils (Extended Data Table 1).

Concerning the age distribution in the subset of tropical grasslands and forests (Fig. 2 and Extended Data Table 3), the mean value of $\Delta C_{\text {rel }}$ is very low $(0.02 \pm 0.03$; \pm s.e.m. $)$, close to steady state, and $\Delta C_{\text {rel }}$ does not depend on time, and therefore does not affect the estimated mean age distribution, but does contribute to the random dispersion of results.

Finally, we included neither previous vegetation as an explanatory variable in the statistical models of the proportion of new carbon, nor carbon change, because of the covariance of $\Delta C_{\text {rel }}$ with land use. Furthermore, sites with previous or present croplands may have experienced a complex land-use history involving ancient primary forests and possibly pasture events. Taking all land-use histories into account would become a case-by-case study.

On the basis of this analysis of the inference of vegetation changes, we conclude that perturbation did not bias our estimates of the mean depth distribution of new carbon; that is, this depth distribution depends on the present vegetation and conditions, and not on previous vegetation, nor is it affected by non-steady-state conditions, in any systematic direction. The impact of perturbation on the proportion of new carbon in topsoils nevertheless prevented us from integrating our data towards global estimates of the absolute amount of new carbon or global carbon turnover. We thus restricted global integration to the depth distribution and median depth of new carbon.

\section{Data availability}

The raw primary data, calculated data and ancillary information analysed and generated here are available in the INRA public repository (http://dx.doi.org/10.15454/KMNR6R). No statistical methods were used to predetermine sample size.

31. New, M., Lister, D., Hulme, M. \& Makin, I. A high-resolution data set of surface climate over global land areas. Clim. Res. 21, 1-25 (2002).

32. Alexander, E. B. Bulk densities of California soils in relation to other soil properties. Soil Sci. Soc. Am. J. 44, 689-692 (1980).

33. Šantrůčková, H. et al. Significance of dark CO2 fixation in arctic soils. Soil Biol. Biochem. 119, 11-21 (2018).

34. Efron, B. \& Tibshirani, R. J. An Introduction to the Bootstrap (Chapman and Hall, Boca Raton, 1993). 


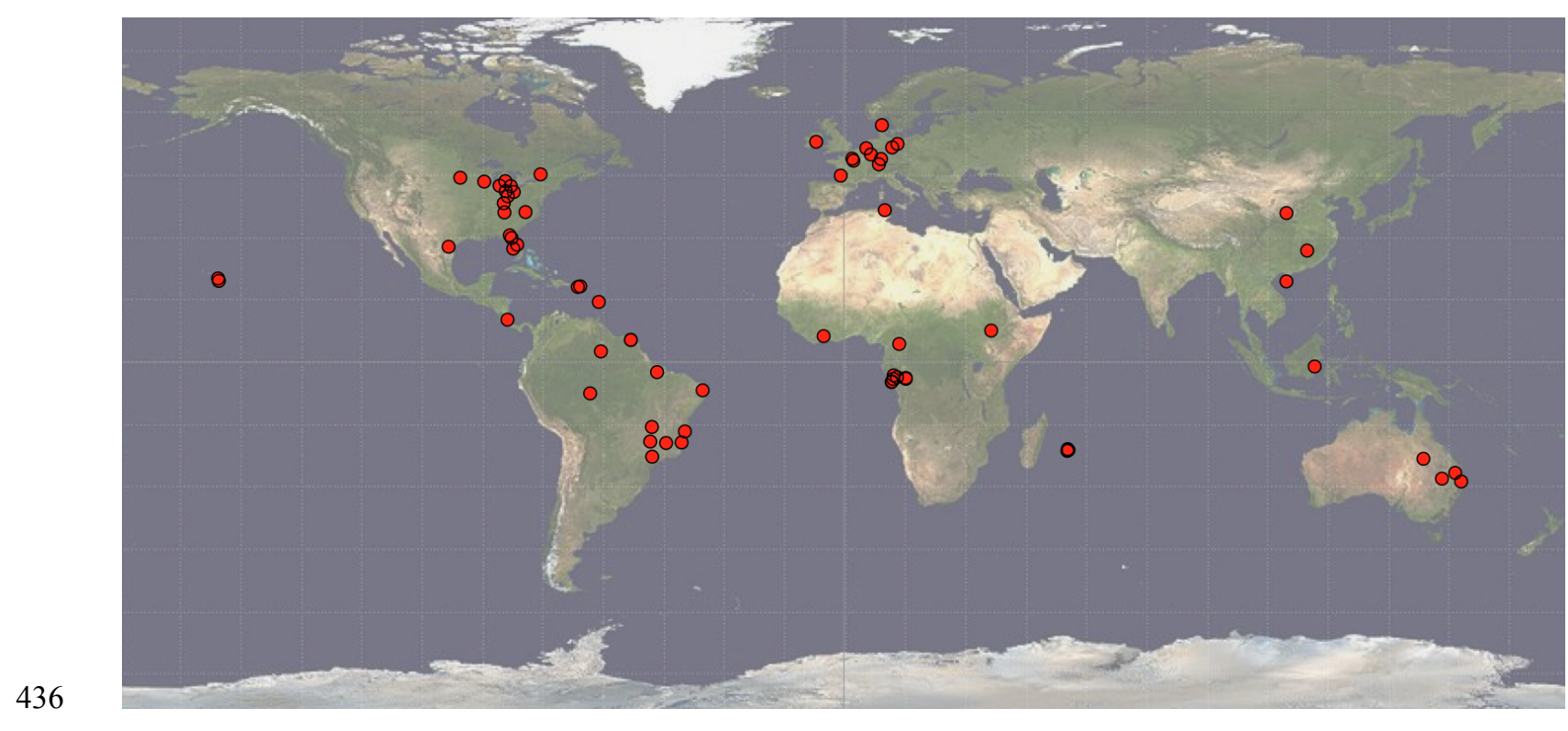

437 Extended Data Fig. 1 | Locations of the study sites. Source of background image: Visible 438 Earth, NASA. 

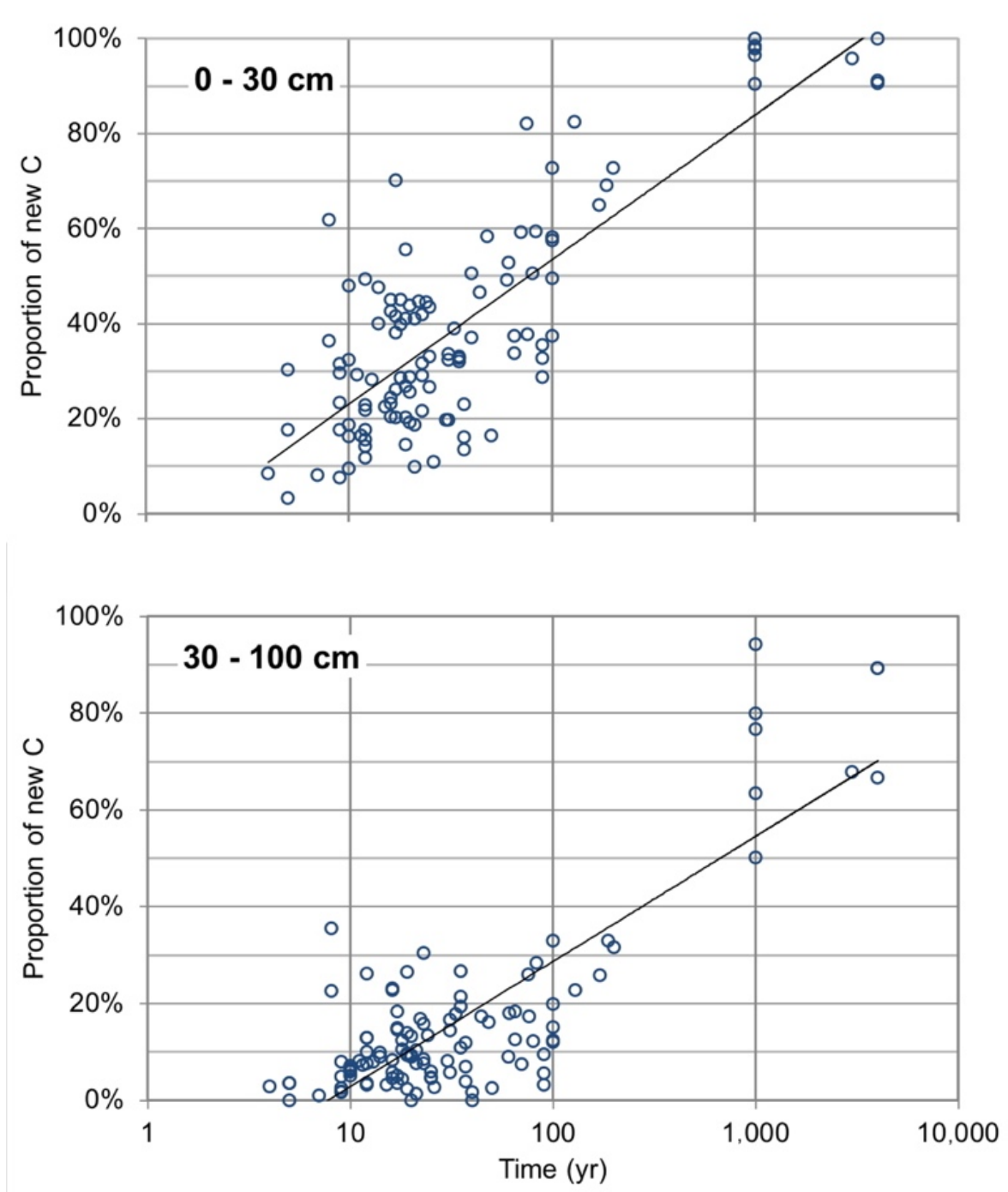

Extended Data Fig. 2 | Kinetics of new-carbon incorporation for the depth layers 0-30 cm and 30-100 cm. The respective logarithmic regressions $y=0.30 \times \log _{10}(x)-0.07$ for $0-30 \mathrm{~cm}$ and $y=0.26 \times \log _{10}(x)-0.23$ for $30-100 \mathrm{~cm}$ indicate that the duration required to replace onethird of the carbon is on average seven times longer in the subsoil than the topsoil. 


\begin{tabular}{lccccc}
\hline & $\begin{array}{c}\text { Coefficient } \\
\text { estimate }\end{array}$ & $\begin{array}{c}\text { Standard } \\
\text { error }\end{array}$ & $T$ value & $\operatorname{Pr}(>|T|)$ & \\
\hline Intercept = Forest & -0.00250 & 0.0728 & -0.034 & 0.973 & \\
Grassland & -0.0531 & 0.0405 & -1.311 & 0.193 & \\
Cropland & -0.0951 & 0.0328 & -2.896 & 0.00472 & ** \\
Log10(time) & 0.258 & 0.038 & 6.865 & $7.6 \mathrm{e}-10$ & $* * *$ \\
MAT & 0.00595 & 0.00234 & 2.540 & 0.0128 & * \\
P/PET & -0.0441 & 0.0337 & -1.306 & 0.1954 & \\
Clay & -0.000566 & 0.000693 & -0.816 & 0.417 & \\
\hline
\end{tabular}

448 Extended Data Table 1 | Proportion of new carbon in topsoil: multivariate linear 449 regression

450 The dependent variable is the ratio of new carbon (derived from the vegetation after time $t$ ) to 451 total organic carbon in the topsoil layer. The explanatory variables are land use (grassland or 452 cropland), $\log 10(t)$ (in years), mean annual temperature (MAT, in ${ }^{\circ} \mathrm{C}$ ), ratio of annual precipitation to evapotranspiration (P/PET), and topsoil clay content (as a percentage). The reference land use (intercept) is forest. $T$ is the value of Student's statistics; $\operatorname{Pr}(>|\mathrm{T}|$ is the probability value of the Student's test.

$456 \quad * P<0.05 ; * * P<0.01 ; * * * P<0.001$.

457 Residual standard error, 0.1249 on 92 degrees of freedom; multiple $R^{2}, 0.4781$; adjusted $R^{2}$, $0.444 ; F$-statistic, 14.04 on 6 and 92 degrees of freedom; $P$-value, $2.768 \times 10^{-11}$. 


\begin{tabular}{|c|c|c|c|c|c|}
\hline & $\begin{array}{c}\text { Coefficient } \\
\text { estimate }\end{array}$ & $\begin{array}{c}\text { Standard } \\
\text { error }\end{array}$ & $T$ value & $\operatorname{Pr}(>\mid T)$ & \\
\hline Intercept = Forest & 0.0205 & 0.0433 & 0.474 & 0.637 & \\
\hline Grassland & -0.0136 & 0.0241 & -0.564 & 0.574 & \\
\hline Cropland & 0.0024 & 0.0195 & 0.121 & 0.904 & \\
\hline Log10(time) & 0.0849 & 0.0223 & 3.806 & 0.00025 & *** \\
\hline MAT & 0.00216 & 0.00139 & 1.551 & 0.124 & \\
\hline P/PET & -0.0516 & 0.0201 & -2.570 & 0.0118 & * \\
\hline Clay & 0.000018 & 0.000412 & 0.045 & 0.965 & \\
\hline
\end{tabular}

461 Extended Data Table 2 | Proportion of new carbon in subsoil: multivariate linear 462 regression

463 The dependent variable is the ratio of new carbon (derived from the vegetation after time $t$ ) to 464 total organic carbon in the subsoil layer. See Extended Data Table 1 for further definitions. 465 Residual standard error, 0.07424 on 92 degrees of freedom multiple $R^{2}, 0.2561$; adjusted $R^{2}$, $466 \quad 0.2076 ; F$-statistic, 5.279 on 6 and 92 degrees of freedom; $P$-value, 0.0001028 


\begin{tabular}{|c|c|c|c|c|c|c|}
\hline Depth & $a_{1}$ & $k 1\left(\mathrm{yr}^{-1}\right)$ & $a_{2}$ & $k_{2}\left(y r^{-1}\right)$ & $a_{1}+a_{2}$ & $\begin{array}{c}\text { Standard deviation } \\
\text { of residuals }\end{array}$ \\
\hline \multirow[t]{2}{*}{$0 \mathrm{~cm}$} & 0.614 & 0.21 & 0.34 & 0.0073 & 0.95 & 0.18 \\
\hline & $(0.47,0.75)$ & $(0.11,2.8)$ & $(0.2,0.49)$ & $(0.0024,0.0158)$ & $(0.92,1.0)$ & \\
\hline \multirow[t]{2}{*}{$10 \mathrm{~cm}$} & 0.287 & 0.15 & 0.67 & 0.0059 & 0.96 & 0.11 \\
\hline & $(0.19,0.40)$ & $(0.08,0.5)$ & $(0.56,0.77)$ & $(0.0028,0.0083)$ & $(0.94,1.0)$ & \\
\hline \multirow[t]{2}{*}{$20 \mathrm{~cm}$} & 0.108 & 0.23 & 0.85 & 0.0047 & 0.95 & 0.09 \\
\hline & $(0.05,0.19)$ & $(0.09,1.5)$ & $(0.78,0.92)$ & $(0.0025,0.0072)$ & $(0.92,1.0)$ & \\
\hline \multirow[t]{2}{*}{$30 \mathrm{~cm}$} & 0.074 & 0.24 & 0.86 & 0.0035 & 0.93 & 0.10 \\
\hline & $(0.02,0.13)$ & $(0.13,1.5)$ & $(0.8,0.93)$ & $(0.0020,0.0064)$ & $(0.88,1.0)$ & \\
\hline \multirow[t]{2}{*}{$40 \mathrm{~cm}$} & 0.070 & 0.23 & 0.83 & 0.0026 & 0.90 & 0.10 \\
\hline & $(0.03,0.13)$ & $(0.09,1.0)$ & $(0.74,0.93)$ & $(0.0014,0.0041)$ & $(0.83,1.0)$ & \\
\hline \multirow[t]{2}{*}{$50 \mathrm{~cm}$} & 0.066 & 0.21 & 0.80 & 0.0020 & 0.87 & 0.09 \\
\hline & $(0.04,0.11)$ & $(0.10,0.5)$ & $(0.70,0.95)$ & $(0.0010,0.0030)$ & $(0.79,1.0)$ & \\
\hline \multirow[t]{2}{*}{$60 \mathrm{~cm}$} & 0.065 & 0.20 & 0.75 & 0.0018 & 0.82 & 0.10 \\
\hline & $(0.03,0.11)$ & $(0.10,0.4)$ & $(0.65,0.89)$ & $(0.0008,0.0028)$ & $(0.73,0.94)$ & \\
\hline \multirow[t]{2}{*}{$70 \mathrm{~cm}$} & 0.052 & 0.22 & 0.71 & 0.0016 & 0.76 & 0.10 \\
\hline & $(0.02,0.09)$ & $(0.13,0.5)$ & $(0.62,0.88)$ & $(0.0007,0.0024)$ & $(0.67,0.95)$ & \\
\hline \multirow[t]{2}{*}{$80 \mathrm{~cm}$} & 0.044 & 0.25 & 0.65 & 0.0016 & 0.70 & 0.11 \\
\hline & $(0.01,0.08)$ & $(0.15,3.2)$ & $(0.54,0.92)$ & $(0.0005,0.0024)$ & $(0.60,0.93)$ & \\
\hline \multirow[t]{2}{*}{$90 \mathrm{~cm}$} & 0.042 & 0.25 & 0.60 & 0.0016 & 0.64 & 0.11 \\
\hline & $(0.01,0.08)$ & $(0.14,3.5)$ & $(0.46,0.99)$ & $(0.0003,0.0025)$ & $(0.51,1.0)$ & \\
\hline \multirow[t]{2}{*}{$100 \mathrm{~cm}$} & 0.048 & 0.25 & 0.55 & 0.0014 & 0.60 & 0.11 \\
\hline & $(0.01,0.08)$ & $(0.14,3.3)$ & $(0.44,0.99)$ & $(0.0002,0.0025)$ & $(0.48,1.0)$ & \\
\hline
\end{tabular}

469 Extended Data Table 3 | Age distribution of carbon over 55 tropical grassland and forest 470 soil profiles

471 These data were used to generate Fig. 2. At each depth, the proportion $f_{\text {new }}$ of carbon aged less 472 than $t$ was fitted by a nonlinear regression of time $t$ using the equation $473 f_{\text {new }}=a_{1} \cdot\left[1-\exp \left(-k_{1} \times t\right)\right]+a_{2} \cdot\left[1-\exp \left(-k_{2} \times t\right)\right]$. Such bi-exponential functions ${ }^{30}$ describe 474 carbon age distribution, with carbon divided into three age classes, $a_{1}$ being the proportion of 'young' carbon, $a_{2}$ the proportion of 'old' carbon, and $\left(1-a_{1}-a_{2}\right)$ the proportion of carbon with an infinite age. $1 / k_{1}$ and $1 / k_{2}$ are the mean ages of young and old carbon, respectively. Numbers in parentheses denote the $95 \%$ confidence intervals of the estimated parameters. The median environmental conditions of the soil set are: $\mathrm{MAT}=23.6{ }^{\circ} \mathrm{C}$; annual precipitation $=2,100 \mathrm{~mm}$; P/PET $\left(\right.$ ref. $\left.^{23}\right)=1.44$ and topsoil clay content $=37 \%$. 


\begin{tabular}{|c|c|c|c|c|c|}
\hline & $\begin{array}{l}\text { Coefficient } \\
\text { estimate }\end{array}$ & $\begin{array}{c}\text { Standard } \\
\text { error }\end{array}$ & $T$ value & $\operatorname{Pr}(>|T|)$ & \\
\hline Intercept = Forest & 0.193 & 0.049 & 3.979 & 0.00014 & *** \\
\hline Grassland & 0.0218 & 0.03499 & 0.624 & 0.534 & \\
\hline Cropland & 0.105 & 0.029 & 3.646 & 0.00044 & *** \\
\hline Time (yr) & 0.000369 & 0.000320 & 1.155 & 0.251 & \\
\hline $\operatorname{MAT}\left({ }^{\circ} \mathrm{C}\right)$ & 0.00381 & 0.00206 & 1.848 & 0.0677 & \\
\hline P/PET & -0.0996 & 0.0297 & -3.354 & 0.00116 & $* *$ \\
\hline Clay (\%) & 0.000638 & 0.000608 & 1.049 & 0.297 & \\
\hline
\end{tabular}

482 Extended Data Table 4 | Depth incorporation of new carbon in subsoil: multivariate linear 483 regression

484 The dependent variable is the ratio of the amount of new carbon (derived from the vegetation 485 after time $t$, in $\mathrm{kg} \mathrm{m}^{-2}$ ) in the subsoil layer to the amount of new carbon in the entire top metre486 that is, $R_{30-100}=C_{\text {new }}(30$ to $100 \mathrm{~cm}) / C_{\text {new }}(0$ to $100 \mathrm{~cm})$. See Extended Data Table 1 for further 487 definitions. Note the dependence on time: the maximum value of the coefficient at the $95 \%$ 488 confidence level (estimate +2 s.e.m.) is $0.001 \mathrm{yr}^{-1}$. Residual standard error, 0.11 on 92 degrees 489 of freedom; multiple $R^{2}, 0.2387$; adjusted $R^{2}, 0.1891 ; F$-statistic, 4.808 on 6 and 92 degrees of 490 freedom; $P$-value, 0.0002618 


\begin{tabular}{lccccc}
\hline & $\begin{array}{c}\text { Coefficient } \\
\text { estimate }\end{array}$ & $\begin{array}{c}\text { Standard } \\
\text { error }\end{array}$ & $T$ value & $\operatorname{Pr}(>\mid T)$ & \\
\hline Intercept = Forest & 11.3 & 2.183 & 5.174 & $1.31 \mathrm{e}-06$ & $* * *$ \\
Grassland & 3.93 & 1.463 & 2.689 & 0.00849 & $* *$ \\
Cropland & 8.77 & 1.28 & 6.842 & $8.18 \mathrm{e}-10$ & $* * *$ \\
Time $(\mathrm{yr})$ & 0.0201 & 0.0137 & 1.466 & 0.146 & \\
MAT $\left({ }^{\circ} \mathrm{C}\right)$ & 0.183 & 0.089 & 2.045 & 0.0437 & $*$ \\
P/PET & -5.11 & 1.32 & -3.871 & 0.000202 & $* * *$ \\
\hline
\end{tabular}

493 Extended Data Table 5 | Median depth of new carbon: multiple linear regression.

494 The dependent variable is the median depth (in $\mathrm{cm}$ ) of the amount of new carbon (carbon 495 derived from the vegetation after time $t$, in $\mathrm{kg} \mathrm{m}^{-2}$ ) of each profile. See Extended Data Table 1 496 for $f$ urther definitions. Residual standard error, 4.963 on 93 degrees of freedom; multiple $R^{2}$, 497 0.3985; adjusted $R^{2}, 0.3662 ; F$-statistic, 12.32 on 5 and 93 degrees of freedom; $P$-value: $498 \quad 3.551 \times 10^{-9}$. 


\begin{tabular}{|c|c|c|c|c|}
\hline & $\begin{array}{l}\text { Observed } \\
\text { Forests }\end{array}$ & $\begin{array}{l}\text { Observed } \\
\text { Grasslands }\end{array}$ & $\begin{array}{l}\text { Observed } \\
\text { Croplands }\end{array}$ & $\begin{array}{l}\text { Global } \\
\text { estimate }\end{array}$ \\
\hline \multirow[t]{2}{*}{$0-10 \mathrm{~cm}$} & 0.538 & 0.511 & 0.321 & 0.521 \\
\hline & $(0.048)$ & $(0.071)$ & (0.032) & $(0.046)$ \\
\hline \multirow[t]{2}{*}{$10-20 \mathrm{~cm}$} & 0.174 & 0.188 & 0.237 & 0.189 \\
\hline & $(0.026)$ & (0.021) & (0.019) & $(0.020)$ \\
\hline \multirow[t]{2}{*}{$20-30 \mathrm{~cm}$} & 0.084 & 0.092 & 0.159 & 0.098 \\
\hline & $(0.016)$ & $(0.020)$ & $(0.017)$ & $(0.017)$ \\
\hline \multirow[t]{2}{*}{$30-40 \mathrm{~cm}$} & 0.052 & 0.056 & 0.091 & 0.056 \\
\hline & $(0.012)$ & (0.012) & $(0.013)$ & (0.009) \\
\hline \multirow[t]{2}{*}{$40-50 \mathrm{~cm}$} & 0.037 & 0.045 & 0.065 & 0.040 \\
\hline & $(0.007)$ & $(0.011)$ & $(0.010)$ & $0.008)$ \\
\hline \multirow[t]{2}{*}{$50-60 \mathrm{~cm}$} & 0.032 & 0.028 & 0.037 & 0.030 \\
\hline & $(0.007)$ & $(0.010)$ & $(0.007)$ & $0.008)$ \\
\hline \multirow[t]{2}{*}{$60-70 \mathrm{~cm}$} & 0.024 & 0.022 & 0.026 & 0.022 \\
\hline & $(0.006)$ & $(0.010)$ & $(0.005)$ & $0.006)$ \\
\hline \multirow[t]{2}{*}{$70-80 \mathrm{~cm}$} & 0.023 & 0.022 & 0.023 & 0.021 \\
\hline & $(0.007)$ & (0.009) & $(0.005)$ & (0.006) \\
\hline \multirow[t]{2}{*}{$80-90 \mathrm{~cm}$} & 0.014 & 0.020 & 0.019 & 0.013 \\
\hline & $(0.006)$ & $(0.007)$ & $(0.004)$ & (0.007) \\
\hline \multirow[t]{2}{*}{$90-100 \mathrm{~cm}$} & 0.013 & 0.018 & 0.017 & 0.011 \\
\hline & (0.005) & (0.007) & $(0.004)$ & (0.008) \\
\hline
\end{tabular}

502 Extended Data Table 6 | Depth distribution of carbon transferred from atmosphere to 503 SOM in 1965-2015

504 These data were used to generate Fig. 3. The amount of new carbon transferred from the 505 atmosphere to SOM in 1965 to 2015 (<50 yr carbon) in each 10-cm layer is expressed as a 506 proportion of the total new carbon $<50 \mathrm{yr}$ in the first metre. The data shown are mean values 507 for observed forests, grasslands and croplands, and global estimates; the numbers in parentheses 508 are the $95 \%$ confidence intervals on the mean or estimate. 